\title{
Neuroblastoma in an Adult causing Spinal Cord Compression: Report of a Case and Review of the Literature
}

\author{
J. I. Urios ${ }^{1}$, L. R. Garceran ${ }^{2}$, T. V. Rosell ${ }^{3}$ \\ ${ }^{1}$ Resident of Rehabilitation Medicine, Hospital de Traumatologia y Rehabilitación; \\ C. S. Vall d'Hebron, Barcelona, Spain, ${ }^{2}$ Senior Staff of Rehabilitation Medicine, \\ Spinal Cord Injury Unit, 'Hospital de Traumatologia y Rehabilitación', C. S. Vall \\ d'Hebron, Barcelona, Spain, ${ }^{3}$ Department of Pathology, 'Facultad de Medicina, \\ Universidad Autonoma de Barcelona,'Barcelona, Spain.
}

\begin{abstract}
Summary
Adult neuroblastoma $(A N B)$ is an uncommon malignancy, there being only 42 reported cases in the world literature. The purpose of this report is to present a case of $A N B$ with spinal cord compression by an intraspinal component, and review methods of diagnosis and treatment.

$N B$ is one of the most frequent childhood malignancies $(90 \%$ of the patients are less than 10 years old) and both pathologists and clinicians tend to exclude it from differential diagnosis when the patient is an adult.

When the tumour is located in the paraspinal region, local extension through the intervertebral foramen into the spinal canal can occur in a dumbbell fashion, a pattern of growth first described by Weber in 1856.
\end{abstract}

Key words: Adult neuroblastoma, Dumbbell neuroblastoma; Spinal cord compression.

NB is an embryonic tumour of neural crest origin. This explains three notable features (1) the spectrum of histologic forms (2) the diverse location of primary foci, and (3) The ability to produce catecholamines.

The incidence of paediatric cases is only 500 per year in the USA. Adult cases are even rarer (Simone et al., 1982). Within the last few years, a number of reports dealing with ANB have appeared in the literature, and we can now say that this neoplasm occurs in all age groups (Mackay et al., 1976).

The anatomical distribution of NB reflects that of the sympathetic nervous system.

There are published reports on ANB that suggest a predilection for sites of involvement which differ from those seen in childhood NB, e.g. head and neck $(13.3 \%)$ or lower extremities $(10 \%)$ (Mackay et al., 1976; Aleshire et al., 1985). Other authors have reported ANB with primary disease sites similar to those seen in paediatric neuroblastoma (PNB), e.g. thorax 20\% (PNB cases $20.3 \%$ ) and abdomen $50 \%$ (PNB cases $63 \%$ ) (Kaye et al., 1986).

Based on histopathologic observations it was assumed that NB seen in children (PNB) and adults (ANB) have similar cell origin (neuroectodermal origin) (Aleshire et al., 1985; Eto et al., 1986; Vinores et al., 1984). 


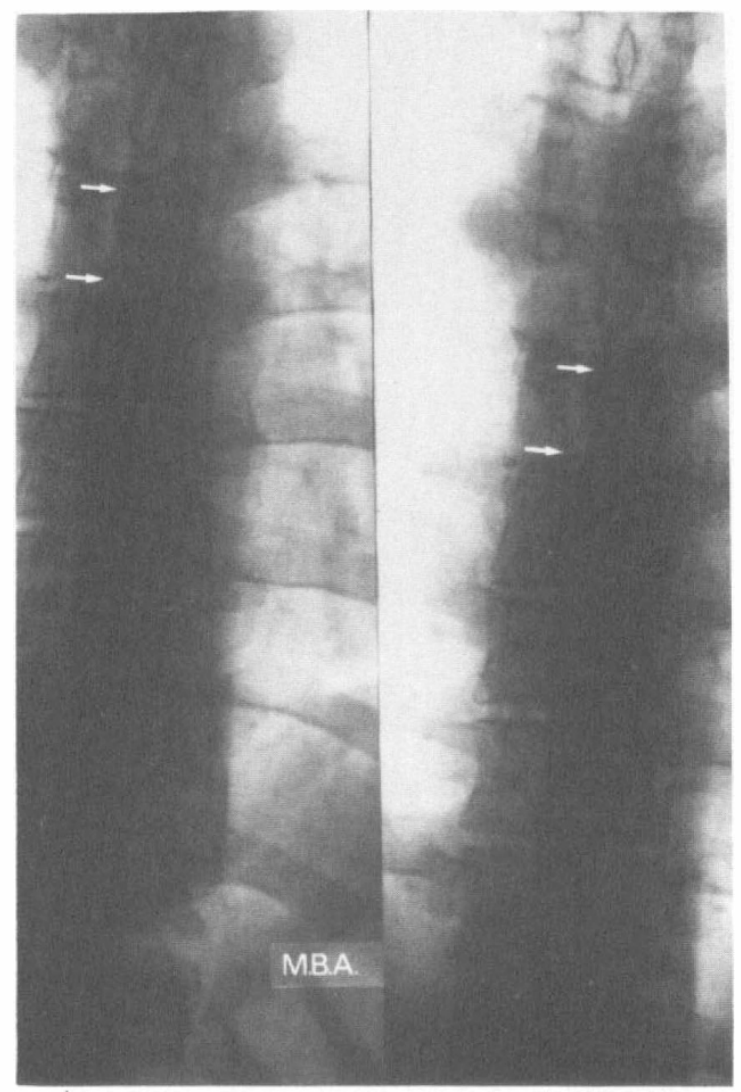

Figure 1 Myelography showing an extrathecal compression at T6-T7 level (Arrows).

Neurogenic tumours are among the most common neoplasms of the mediastinum and are seen in the posterior mediastinum in the paravertebral area, whence local extension through the intervertebral foramen in a dumbbell or hourglass fashion into the spinal canal can occur. In most instances this cancer presents signs and symptoms of spinal cord compression. Mediastinal tumours have a greater tendency to extend into the spinal canal than retroperitoneal tumours (Holgersen et al., 1983).

\section{Case Report}

In December, a 30-year-old man presented with a month's history of thoracic back pain, of moderate to severe intensity, radicular in distribution and accompanied in the last 10 days by lower-limb weakness and numbness.

Clinical examination showed weakness of the lower limbs with clinical signs consistent with cord compression at T6 neurological level. A chest X-ray was normal. Myelography showed an extrathecal compression at T6-T7 level (Fig. 1). Because of the history, 


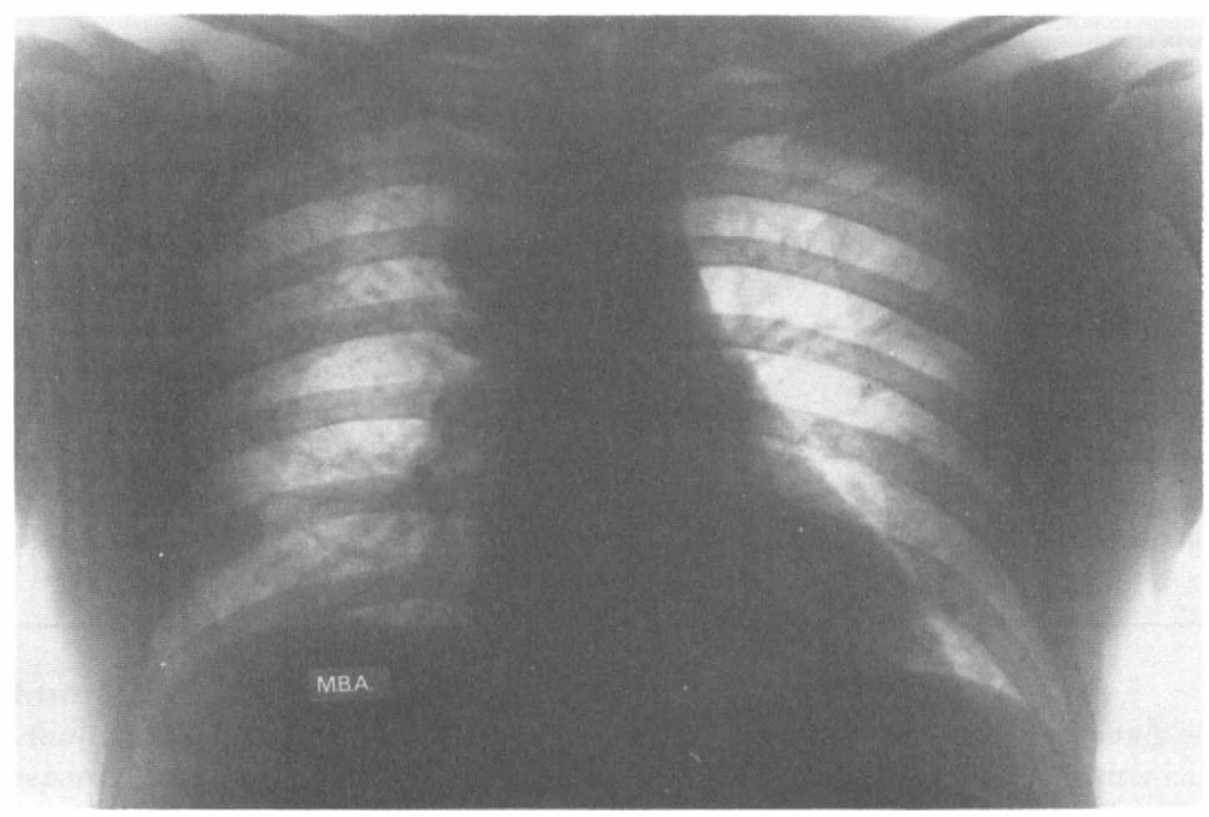

Figure 2 Chest $\mathrm{X}$-ray showing a broad mediastinum and a right paraspinal mass.

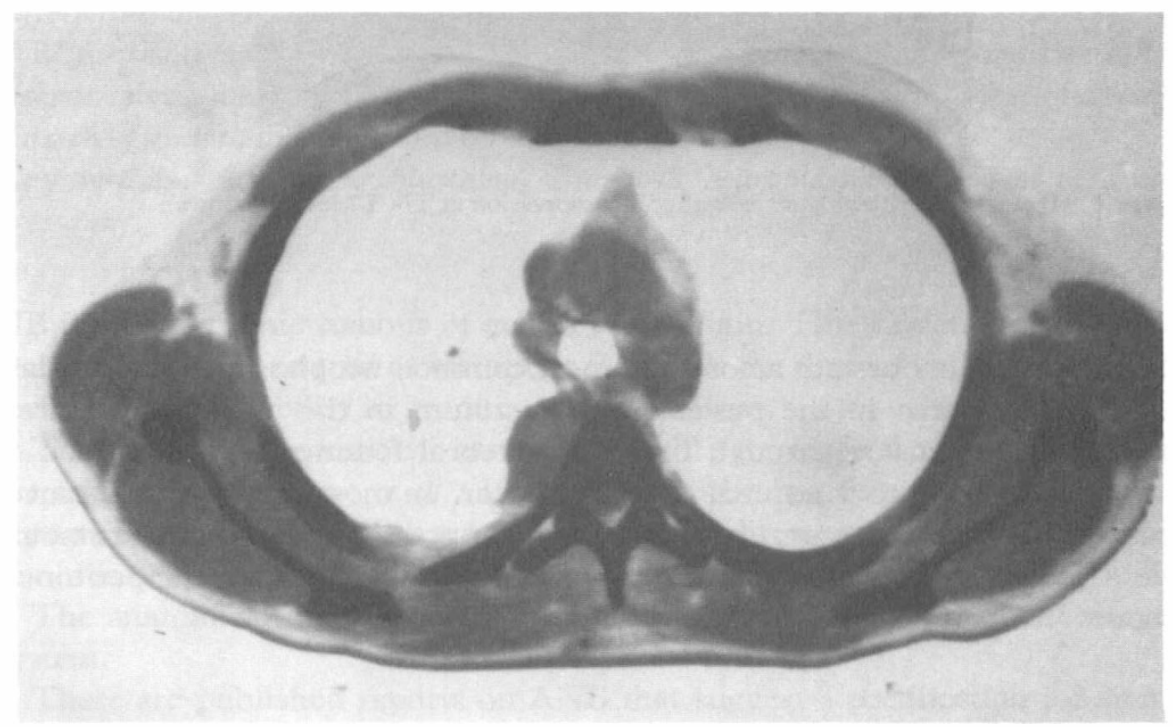

Figure 3 CT Scan showing a right paraspinal mass and a little pleural effusion.

clinical signs and radiological findings, a T6--T7 laminectomy was done. The biopsy only showed normal epidural fat.

The patient did not improve after surgery and more exhaustive radiological studies were done. A chest X-ray now showed a broad mediastinum (Fig. 2). Spinal X-rays and 


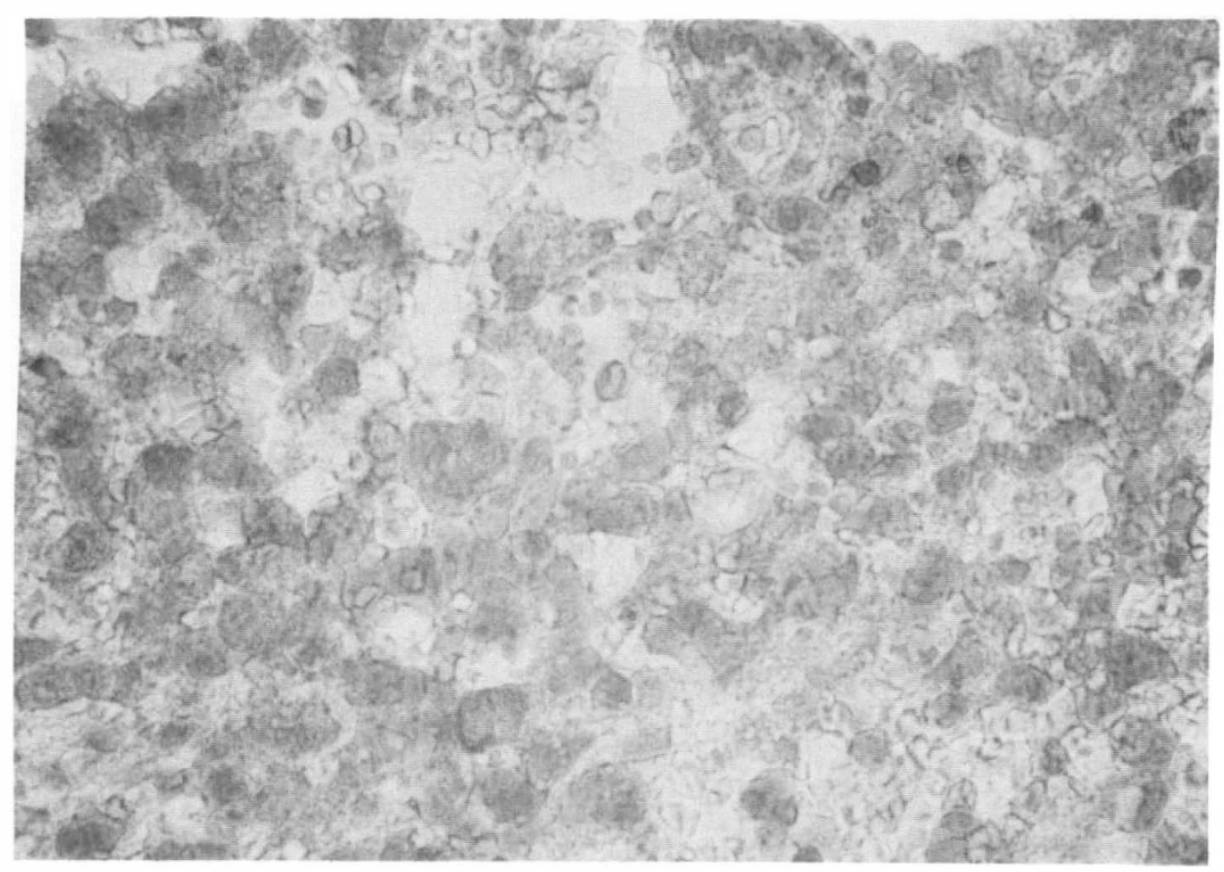

Figure 4 Histological features: small dark cells with round to oval hyperchromatic nuclei and scanty cytoplasm. NSE positive (red).

a radionuclide scan were normal. A CT scan showed a right paraspinal mass and a small pleural effusion (Fig. 3).

In April, 5 months after the onset of symptoms at the T6 level, severe pain of a radicular nature and clinical signs consistent with cord compression at the $T 1$ level developed. Therefore an exploratory thoractomy was done. There was a pleural effusion, a dilated, thrombosed vena azygos and a paraspinal mass with local extension through the fourth right thoracic intervertebral foramen.

The biopsy showed an undifferentiated tumour consisting of small dark cells defined by round to oval hyperchromatic nuclei and scanty cytoplasm. Various sized islands of small round cells were found. Immunocychemistry was carried out and Neuron Specific Enolase (NSE) was positive; S-100 protein was also positive (Fig. 4). Common Leucocyte Antigen and Epithelial Membrane Antigen were negative.

Because of the location and the histological and immunocytochemistry characteristics we can say that this tumour exhibited features of NB.

Examination of the sternal bone marrow showed infiltration with round cells bearing scanty cytoplasm which were described as nonhematopoeitic. Catecholamines in the blood and urine were normal. Electron microscopy studies were not done; there was no autopsy. The patient began treatment, first with radiotherapy (4000 rads) over the cervical and thoracic spine. After one dose of radiotherapy, chemotherapy was started with dexamethasone plus cyclophosphamide and adriamycin. After the first cycle the neurological situation was stable, but he developed an abscess in the gluteal region and therefore the treatment was discontinued. Ten months after beginning treatment, there was radiological evidence of disseminated disease, and a month later, 16 months after the onset of illness, the patient died. 


\section{Discussion}

The difficulty of establishing a diagnosis of ANB is a reality (Mackay et al., 1976; Reynolds et al., 1981; Kaye et al., 1986; Eto et al., 1986). NB in general occurs with spinal cord compression in only 1 to $4 \%$ of cases (Punt et al., 1980; Reyne et al., 1986). The symptoms of onset may include pain, particularly radicular pain, limb weakness, urinary retention and constipation or loss of sphincter control and paraplegia. The average age at presentation was 34 (range 16-75) in the world literature. The duration of symptoms before the diagnosis could be made and surgery carried out has been between 6 weeks to 84 months in the various reports (Akwari et al., 1978; King et al., 1976).

When involvement of the bladder and rectal sphincters was observed, this were associated with severe and irreversible compression of the spinal cord.

It is evident that early and accurate diagnosis can prevent severe neurological changes and prolonged morbidity (Balakrishnan et al., 1974; King et al., 1975; Punt et al., 1980, Massad et al., 1985).

Because osseous metastases are frequent, spinal cord compression is common in the terminal stages of NB in general (Punt et al., 1979). Most NB arise in an adrenal gland, but $16^{\circ}{ }_{\circ}$ originate in the sympathetic ganglia (Siegel et al., 1986). The pathologist must consider ANB in the differential diagnosis of all small cell neoplasms affecting the adult population (Reynolds et al., 1981; Aleshire et al., 1985; Kaye et al., 1986).

There is difficulty in establishing a diagnosis of ANB, especially if conventional light microscopy alone is used. ANB is among the histological group of 'small dark cell tumours' defined by cells that are $12 \mu \mathrm{m}$ in diameter with round to oval hyperchromatic nuclei and scanty cytoplasm which often exhibit HomerWright rosette formation (Aleshire et al., 1985). Electron microscopy helps to establish an exact diagnosis of ANB. Long cytoplasmic processes resembling axons or dendrites and synaptic junctions are two findings which indicate ANB with electron microscopy (Misugi et al., 1968; Mackay et al., 1976; Hashimoto et al., 1983; Aleshire et al., 1985; Kaye et al., 1986.). Dense core neurosecretory granules, microtubules and intermediate filaments are other characteristics of ANB, but they are nonspecific findings.

In adults there is liable to be confusion with lymphomas and undifferentiated small cell carcinomas (In these cases common leucocyte antigen and epithelial membrane antigen are respectively positive). The diagnosis of these tumours should be made by a combination of methods.

NB resulted in excretion of elevated quantities of catecholamines and their by-products. Because measurement of these metabolites is not reported in many of the published cases on ANB, it is unclear whether they are elevated. In $25 \%$ of cases there is no increase of catecholamine excretion. (Gitlow et al., 1970; Dosik et al., 1978.).

Many NB tumour markers are reported like gangliosides, sialic acid containing glycosphingolipids (Ladish et al., 1985); Tetanus toxin (TT) (Berliner et al., 1984); Serum ferritin (Hann et al., 1980); Neuron Specific Enolase (Vinores et al., 1984); S-100 protein and bombesin (Kay et al., 1986), but they are also found in other 'Small dark cell tumours' (Seeger 1982; Beemer et al., 1984) and other tumours of neuronal origin. 
Although the final diagnosis always rests on surgical exploration and histological examination of the tumour, there are multiple radiological studies for evaluating a patient with known or suspected NB (Fagan et al., 1974; Resjo et al., 1979).

If the tumour is paraspinal and the patient has spinal cord involvement myelography and/or a metrizamide CT scan are essential, MRI is a noninvasive procedure which appears to have clinical advantages in evaluating intraspinal neoplasms and their response to therapy. It provides excellent differentiation of soft tissue planes without the need for ionising radiation or contrast injection (Cohen et al., 1984; Siegel et al., 1986; Dietrich et al., 1986). It has been our practice to care for these patients as a team in a multidisciplinary Spinal Cord Injury Unit.

Knowledge of the site of the primary local tumour, its extent, histological degree according to the criteria of Shimada, as well as a precise knowledge of the stage of the disease are essential for proper treatment and prognosis (Evans et al., 1976; Coldman et al., 1980; Shimada et al., 1984; Evans et al., 1987).

Surgery is the mainstay of treatment for patients with localised disease (Akwari et al., 1978; Massad et al., 1985; Allan et al., 1986; Kaye et al., 1986), and chemotherapy for those with metastatic spread (Dosik et al., 1978; Lopez et al., 1980). Radiation therapy is used to treat gross residual disease and may sometimes render an inoperable tumour operable (Massad et al., 1985; Allan et al., 1986; Holperin et al., 1986). Surgical intervention is urgently indicated once an intraspinal component has been defined. There is no assurance that symptoms and signs of compression of spinal cord or other vital structures, e.g. respiratory tract (Akwari et al., 1978) will be resolved after extirpation of the tumour.

Despite the common presentation of adult NB as stage III or IV, in $40 \%$ of cases of ANB, initial aggressive surgical therapy is best (Mackay et al., 1976; Dosik et al., 1978; Lopez et al., 1980; Aleshire et al., 1985). It is essential to search for evidence of disease in other areas. Bone marrow aspiration is essential, regardless of the findings in the peripheral blood.

The prognosis of patients with metastasic NB is poor but may be improved with chemotherapy (Kinnier et al., 1974; Lopez et al., 1980). For those patients who have had aggressive surgery, the median survival is 20.5 months compared with 12.5 months for those not receiving surgery. The median survival of those also receiving chemotherapy was 18 months compared with 13 months in those not receiving chemotherapy (Salaskrishnan et al., 1974; Lopez et al., 1980; Allan et al., 1986; Kaye et al., 1986).

Physical therapy, bracing when necessary and frequent re-evaluation will provide the opportunity for maximal functional rehabilitation. Development of spinal deformity after destruction of spinal components is not a problem in adults although pre-existing deformity may progress. The achievement of complete remission and/or prolongation of survival are realistic aims in the management of NB in adults.

\section{Dedication}

To my Father. 


\section{References}

Akwari OE, Spencer, W, Payne, B et al., 1978 Dumbbell Neurogenic Tumours of the Mediastinum. 53: 353-358. Mayo Clinic Proceedings

Aleshire, SL, Glick AD, Cruz VE, et al. 1985 Neuroblastoma in Adults: Pathologic findings and clinical Outcome. Patholological Laboratory Medicine 109: 352-356

Allan SG, Cornbleed MA, Carmichael J, et al. 1986 Adult Neuroblastoma. Report of three cases and Review of the literature. Cancer 57:2419-2421.

Salakrisshnan V, Rice MS, Simpson DA 1974 Spinal Neuroblastomas. Diagnosis, Treatment and Prognosis Journal of Neurosurgery 40:631-638.

Beemer FA, Vlug AMC, VANVeElen CWM, et al. 1984 Isoenzyme pattern of enolase of childhood tumors. Cancer 54:293-296.

Berliner P, UNSICKeR K 1985 Tetanus Toxin Labeling as a novel rapid and highly specific tool in human neurobl stoma differential diagnosis. Cancer 56:419-423.

Cohen MD, Weetman R, Provisor A, et al. 1984 Magnetic Resonance Imaging (MRI) of neuroblastoma with a D.15 T Magnet American fournal of Roentgenology 143:1241-1243.

Coldman AJ, Fryer CSH, Elwood JM, et al. 1980 Neuroblastoma: Influence of age at diagnosis, stage, tumor site, and sex on prognosis. Cancer 46:1896-1901.

DiETRICH RB, KANGARLOO H 1986 Retroperitoneal mass with intradural extension: Value of Magnetic Resonance Imaging in Neuroblastoma. American fournal of Roentgenology 146:251-254.

Dosik GH, Rodriguez V, Benjamin RS, et al. 1978 Neuroblastoma in adult. Effective combination chemotherapy. Cancer 41:56-63.

Ето H 1986 Adult Neuroblastoma: A case report. Hinyokika Kiyo 32(9):1294-1297.

Evans A, Albo V, O’Angio GJ, et al. 1975 Factors Influencing Survival of children with nonmetastasic Neuroblastoma. Cancer 38:661-666.

Evans A 1980 Staging and Treatment of neuroblastoma. Cancer 45:1799-1802.

Evans A, D’Angio GJ, Propert K, et al. 1987 Prognostic factors in neuroblastoma. Cancer 59:1853-1859.

FAGAN CJ, SwischUCK LE 1974 Dumbell neuroblastoma or Ganglioneuroma of the spinal canal. American fournal of Roentgenology 120:453-460.

Gitlow SE, BERTANi LM, RAUSEN A, et al. 1970 Diagnosis of Neuroblastoma by qualitative and quantitative determination of catecholamine metabolites in urine. Cancer 1377-1383.

Hann HWL, Levy HR, Evans AE 1980 Serum ferritin as a Guide to therapy in Neuroblastoma. Cancer Research 40:1411-1413.

Hashimoto H, Enjoji M, Nakajima T, et al. 1983 Malignant neuroepithelioma (Peripheral Neuroblastoma): A Clinicopathological study of 15 cases. American fournal of Surgery and Pathology 7:309-318.

Holgersen LO, SANTUli TV, Schullinger JN, et al. 1983 Neuroblastoma with intraspinal (dumbbell) extension.. Fournal of Pediatric Surgery 18:406-411.

HolPERIN EC 1986 Radiation therapy in the management of Neuroblastoma. The Duke University Medical Center experience. International fournal of Radiation, Oncology, Biology, Physics 12(10):1829-1837.

Hughes M, Mardsen HB, Palmer MK 1974 Histologic patterns of Neuroblastoma related prognosis and clinical staging. Cancer 34:1706-1711.

KAYE JA, WARHOL MJ, KRETSChMAR C, et al. 1986 Neuroblastoma in adults. Tree case reports and a review of literature. Cancer 58:1149-1157.

KinNier Wilson LM, Draper GJ 1974 Neuroblastoma its natural history and prognosis. A study of 487 cases. British Medical fournal 3:301-307.

King D, Goodman J, Haluk T, et al. 1975 Dumbbell Neuroblastomas in children. Archives of Surgery 110:888-891.

LADISH S, LIANG LU Z 1985 Detection of a tumor associated ganglioside in plasma of patients with neuroblastoma. The Lancet 19.

Lopez R, Karakousis C, RaO U 1980 Treatment of Adult neuroblastoma. Cancer 45:840-844.

MaCkAy B, Luna MA, ButLer J 1976 Adult Neuroblastoma. Electron Microscopic observations in nine cases. Cancer 37:1334-1351.

MaSSAD M, HAdDAD F, SLim M, et al. 1985 Spinal cord compression in Neuroblastoma. Surgical Neurology 23: 567-572.

Misugi K, Misugi N, Newton WA 1968 Fine structural study of neuroblastoma, ganglioneuroblastoma and pheocromocytoma. Archives of Pathology 86:160-170.

Punt J, Pritchard J, Pincott JR, et al. 1980 Neuroblastoma: A review of 21 cases presenting with spinal cord compression. Cancer 45:3095-3101.

RESJO IM, HARDWOOD-NASH DC, FITZ CR, et al. 1979 CT Metrizamide myelography for intraspinal and paraspinal neoplasms in infants and children. American fournal of Roentgenology 132:367-372. 
REYNE J 1986 Dumbbell Neuroblastoma presenting without spinal cord findings. fournal Pediatric Surgery 21(11):995-996.

ReYNolds CP, SMith G, FRENKel EP 1981 The diagnostic dilemma of 'small round cell neoplasm.' Cancer 38:2008-2034.

Shimada H, Chatlen J, Newton WA 1984 Histopathologic prognostic factors in neuroblastic tumors. Fournal of the National Cancer Institute 73:405-416.

SIEGEL: MJ, JAMroz GA, Glazer HS, et al. 1986 Imaging of intraspinal extension of neuroblastoma. Fournal of Computer Assisted Tomography 10:593-595.

Simone JV, Cassady JR, FilleR RM 1982 Cancers of childhood. In: VT De Vita, S Hellmann $S$ Rsenberg (Eds) Cancer: Principles and Practice of Oncology. Lippincott, Philadelphia, pp 1254-1330.

Triche TJ, AsKIN FB 1983 Neuroblastoma and the differential diagnosis of small round, bluecell tumors. Human Pathology 569-595.

VINORES SA, SONNIN JM, RUBINSTEIN LJ, et al. 1984 Immunohistochemical demonstration of NSE in neoplasms of the CNS and other tissues. Archives of Pathology and Laboratory Medicine 108:536-540. 